\title{
Research on the Financial Insurance Fund Against the Background of Mixed Operation*
}

\author{
Shali Zhou \\ Hubei University of Science and Technology \\ Xianning, China 437100
}

\begin{abstract}
The first part of this article briefly describes the related theories of the mixed operation and financial insurance fund. Then, this paper analyzes the development situation of financial insurance fund under the mixed operation; it means that the legislative situation under "finance law" promotes the financial insurance funds transform to the comprehensive legislation form. This paper also discusses that the measures of reasonable ensuring the: rights and interests of the investor and promoting the orderly market competition. From the perspective of diversification, the last part expounds the legislative means of the smooth and safe operation of financial insurance fund under the trend of mixed operation
\end{abstract}

\section{Keywords-mixed operation; finance and insurance; fund}

\section{INTRODUCTION}

With the emergence of financial innovation, the interaction and mutual influence of Banks, insurance, securities and other financial institutions are getting deeper and deeper. Economic integration in the world today, China's financial sector to the outside world and the world began to open, in view of the universal foreign financial sector whitehot competition, China's financial sector ever rule the old idea of "separate operation, separate supervision" is to further shocks. In order to respond to the reform of the financial system around the world, and the western financial system, China's banking industry has been on the verge of a mixed operation. Recently, the banking of our country are trying to explore the mixed management pattern, and refer to foreign advanced experience, for example: most of large and medium size Banks began to interact with funds, insurance, securities and other industries. When in taste mixed management benefits, mixed management in particular focus on the risk of hidden dangers, from the perspective of macro

\author{
Yang $\mathrm{Xu}$ \\ Hubei University of Science and Technology \\ Xianning, China 437100
}

and micro two reinforcement design and control risks, avoid because of the mixed management to systemic financial risk.

In addition, because the financial industry is related to the economic lifeline of the national economy, the changes and adjustments of relevant legislation will not be too fast, and Banks will still have to wait for a period of time to move to full license. This will greatly limit the pace and progress of financial institutions' development of financial insurance business, so it is difficult to see benefits in the short term.

This article from the legislative practices, mixed management pattern reform, financial regulation, network financial, financial institutions are effective strategies for how to develop financial insurance fund business in detail, in order to find out the financial fund of insurance of the future development direction, promote the financial insurance industry in our country the steady development.

\section{OVERVIEW OF MIXED OPERATION AND FINANCIAL INSURANCE}

\section{A. Definitions}

Mixed management refers to the commercial Banks, financial department concerned with specific scientific organization mode in the capital market and money market by variety, means more and more business crossover operation service management model. The mixed operation of financial industry is the general trend of economic development in the world. It is also the preferred mode for China to complete revolution and transformation in the financial industry. See "Fig. 1" for the basic architecture of mixed operation. 


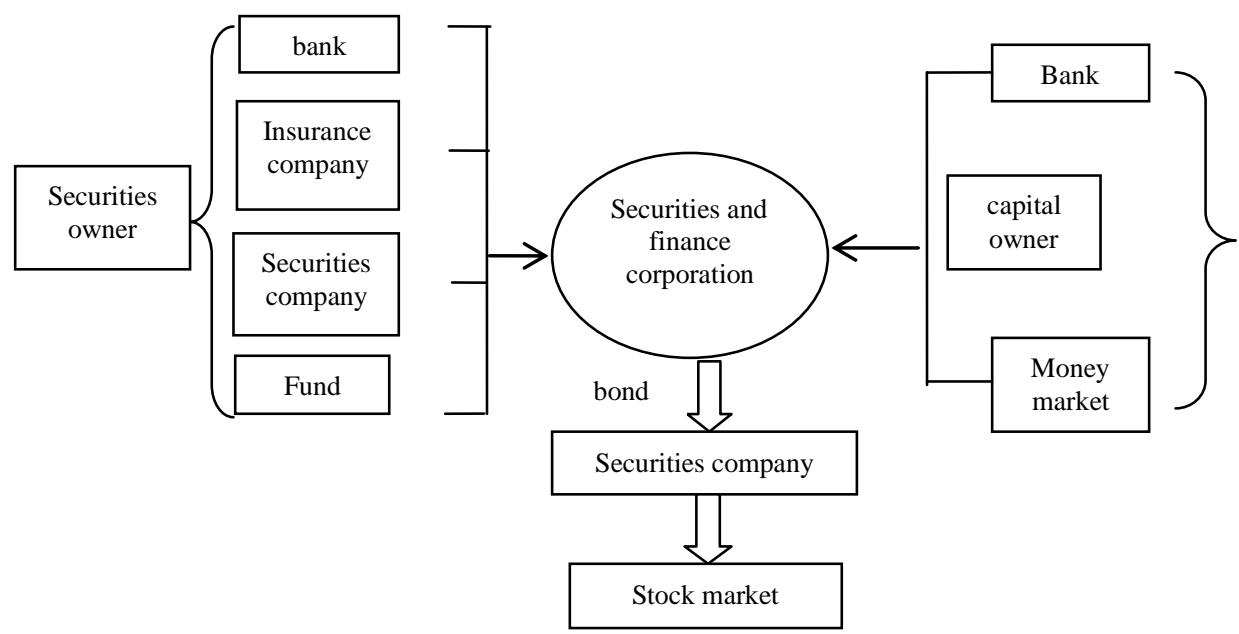

Fig. 1. Basic framework of mixed operation model.

The industry classification of the Shenzhen stock exchange divides the financial insurance index into 13 categories. An insurance fund is an insurance institution that deals with financial risks and other related businesses.

\section{B. The Present Situation of Legislation Management of Financial Insurance Business Under Mixed Operation Mode}

Approval of the state council has agreed to "China insurance investment fund set up plan" (hereinafter referred to as the "scheme"), require insurance regulatory commission jointly with relevant departments to seriously do a good job in China insurance investment fund planning, supervision, etc. All the work, strengthen communication and coordination and supervision, to be responsible for their implementation.

"Solution", points out that in order to serve entity economy development and promote economic quality, the nation established China insurance investment fund (hereinafter referred to as fund). The total size of the fund is estimated to be 300 billion yuan, and the initial period is 100 billion yuan.

According to the plan, the fund is mainly established by insurance institutions according to law, giving full play to the strategic, active and comprehensive investment platform of long-term financial advantages of the insurance industry. Firstly, direct investment fund is to meet the national economic strategy, mixed ownership reform and other market demand. Secondly, as the mother fund have various domestic and foreign investment funds, especially the government and other investment funds similar to the investment field.

The programme notes that the fund adopts a limited partnership, with a general partner and a number of limited partners. Insurance asset management companies and other institutions invest in the establishment of zhongbao investment co., LTD. Zhongbao investment co., LTD., as a general partner, is responsible for the establishment, collection and management of the fund. Limited partners shall be held by qualified investors such as insurance institutions. The establishment, collection and management of funds shall comply with laws and regulations and market rules. Zhongbao investment co., ltd. shall establish a modern enterprise system according to the company law, establish a management team according to the market mode, and establish an effective incentive and restraint mechanism.

"Plan" has been clear about the scope of investment, the fund closely around the national industrial policy and development strategy to carry out investment, mainly in the area along the way ", coordinated development of the beijing-tianjin-hebei region, the Yangtze river economic belt and other strategic projects, constitution and good social and economic benefits of shanty towns transformation, the urban infrastructure, major water conservancy project, the Midwest, traffic facilities, new urbanization, such as infrastructure construction, the international cooperation capacity and major projects of "going out", etc. The fund and the zhongbao investment co., ltd. shall specify the minimum proportion of direct investment in the construction of the infrastructure in the agreement and articles of association. On this basis, the fund can invest in strategic emerging industries, modern logistics, health care, energy resources, information technology, green environmental protection, small and medium enterprises and other fields.

In exit mechanism, the solution is clear, by way of equity investment fund, take the public, the "new three board", equity transfer, share repurchases, equity transfer, exit; Where an investment is made in the form of creditor's rights, the term of the investment and the arrangement for the increase of the credit shall be specified, and the withdrawal shall be due in accordance with the provisions of the investment agreement; In the form of preferred stock or mezzanine funds, the withdrawal mode of share repurchase and equity transfer shall be clarified. The fund shall, in accordance with the relevant provisions and the principles of marketization, agree with the project party on the withdrawal of major adverse circumstances and ensure the safety of the fund's assets.

But because the financial sector is vital to the national economy, it will not be too soon to change and adjust the 
legislation, and Banks will still have to wait a while to move to full licence. This will greatly limit the pace and progress of financial institutions' development of financial insurance business, so it is difficult to see benefits in the short term, see "Table I" for details.

TABLE I. The MiXed Management MOdEL IN THE FinANCIAL AND INSURANCE INDUSTRY

\begin{tabular}{|c|c|c|c|c|c|c|}
\hline Year & 2001 & 2002 & 2003 & 2004 & 2005 & 1-2month of 2006 \\
\hline Insurance cost & 47 & 388 & 765 & 795 & 905 & 261.92 \\
\hline $\begin{array}{l}\text { The proportion of the first } \\
\text { insurance in the year }(\%)\end{array}$ & Less than 3.5 & 17.1 & 26 & 24.8 & 25 & 34 \\
\hline
\end{tabular}

\section{THE FEASIBILITY STRATEGY OF IMPROVING THE BUSINESS OF FINANCIAL INSURANCE FUND UNDER THE BACKGROUND OF MIXED OPERATION}

\section{A. Improve the Legislative Process of the Operation of the Financial Insurance Fund}

Since the beginning of the mixed management of commercial bank "the curtain" gradually open, many Banks are actively and try to layout, mixed management of commercial bank problem is likely to be resolved from the legislative level, but because of "commercial bank law" method, to "full license" bank still needs to wait for some time. Experts and industry insiders said the mixed management will be the new opportunities and new stage of the financial reform in China especially in deepening the reform of state-owned enterprises in an all-round way and promote the strategy of "area" under the background of, mixed management in the banking sector accelerated the pace. In addition, the reform of mixed ownership of Banks and securitization of non-performing loans are expected to usher in new opportunities in the second half of the year.

Concluded from the perspective of legislation in our country, the financial institutions bankruptcy investors protection act: China's financial sector in the financial insurance investors protection legislation level also in quite a lag phase, the financial entity exit the market situation more common, however, most of the financial institutions have operations in relying on aid under the condition of resolving conflict. As of now, China still lacks effective savings protection laws, and only from the perspective of administrative rules and regulations has promulgated the "insurance fund management measures" and other laws and regulations. Therefore, China should refer to the advanced codex document in the international financial field and enter into the bankruptcy protection law of financial institutions under the premise of reference. Make comprehensive financial insurance fund's functions and objectives more clear.

To clarify the functions of the comprehensive financial insurance fund to eliminate the competition environment in the financial market, to carry out the reasonable control of risks in the financial industry and the implementation of the financial entity bankruptcy plan. At the same time, from the legislative perspective, the operation of comprehensive financial insurance fund is smoother; the scope of responsibilities and compensation rules are clearer, and their corresponding functions and powers are clearly defined:
Reasonable supervision of the credit status, risk and risk warning of financial entities;

First, resolve the conflicts and conflicts in the operation of financial insurance fund;

The bankruptcy protection of financial entities should be dealt with in the first place.

Under such a premise, the law gives the mandate:

To obtain corresponding business information;

To clarify the functions and powers of the inspection concerned.

\section{B. Accelerate the Reform of Mixed Ownership and Create a Favorable Policy Environment for the Development of Financial Insurance Fund Business}

The cross-boundary operation of the banking industry is mainly manifested in the acquisition of A shares brokerage license. The bank obtains the brokerage license is the corresponding policy with the interest rate marketization, gives the bank new investment channel, to absorb the impact of the interest rate liberalization. The bank's acquisition of brokerage license will enable Banks to enter the equity investment field, thus enriching the bank's channels in financing business. Generally speaking, the big Banks will be given priority, because the risk control is perfect, and there are $\mathrm{H}$ shares brokerage license. The possible route is to buy AA - share broker with a new or h-share broker. The company will develop a large asset management business first, and then obtain the securities license plate after the conditions are mature.

In addition to the commercial Banks' own motivation, regulators are also "fuelling" the banking industry. The CBRC will actively promote the reform of banking management structure. We will continue to deepen the reform of the divisional system and promote the "branch bank" to "process silver".Transformation: actively promoting the reform of the franchise sector; we will explore the reform of the financial insurance fund business sector and the subsidiary system.

\section{Construct Comprehensive Financial Commodity Investor Protection Fund and Implement the Mode of Functional Financial Supervision}

Functional tend to think of the financial sector, financial regulation and financial products to implement parsing from the perspective of nature, the financial function similar to the implementation of the unified arrangement, the 
implementation of scientific and perfect functional regulation. For example, the UK enacted the financial services and market act in the early 21 st century and implemented comprehensive supervision. In the early 21 st century, the United States enacted the dodd-frank act, which achieved the purpose of omni-directional financial regulation of the federal reserve and so on.

Various phenomena show that all the countries in the world have implemented comprehensive functional supervision in the financial industry. The motivation of this kind of regulation is the use of the financial mixed operation mode, which leads to the cross-business supervision between different financial institutions. But the interactive regulatory system is still lacking. Therefore, its comprehensive functional supervision means also began to appear.

From the global various countries started trend of the function of comprehensive regulation, investor protection fund shall set up comprehensive financial products, in the financial sector to promote the establishment of functional financial regulation mode and use.

\section{The Investor Rights and Interests Miao Town}

Wen Dian strike, enclosed in the financial management of the past, have a clear division of responsibilities between each financial entities separate operation, any financial entity in its own responsibility and duty. Therefore, financial regulation should be carried out on the basis of the actual situation, weighing the functional and special characteristics of the financial industry.

However, along with the continuous development of China's financial industry mixed operation, financial products have alternative insurance products, the trend of the banking, securities and futures products, and the previous finance law to the comprehensive and maintaining investor and consumer interests and rights of people transition, financial services gradually replace the former financial organization mode.

\section{E. Comprehensive Internet Financial Insurance Business Has Advantages}

The data generated by Internet tools such as WeChat, QQ taobao and 360 were collected and analyzed, and many financial services were extended (as shown in figure 2). For example, consumer finance, credit CARDS, housing loans and taobao shop loans. From these extensions, it can be seen that Internet finance is a kind of promotion of traditional finance, which can effectively supplement the indirect financing channels currently dominated by China's banking industry. In the global wi-fi era, bank financial planners can operate remotely through the Internet at different locations through the Internet. The integration of the Internet will inevitably promote the sustainable development of traditional financial insurance business in a more convenient and professional direction. With sun's lying down, and the number of lok stations.

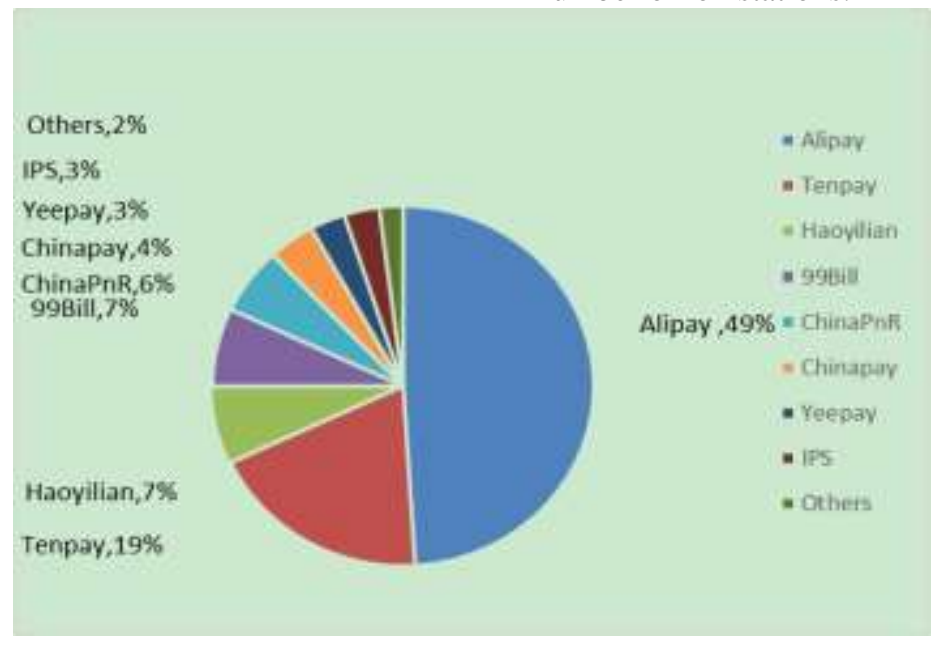

Fig. 2. Mixed operation in network management.

\section{RESEARCH ON THE FINANCIAL INSURANCE BUSINESS OF PING'AN BANK UNDER THE BACKGROUND OF MIXED OPERATION}

In 2014, Ping'an life officially received "the approval of Ping'an life insurance".

The approval of the sales qualification of the securities investment fund of the limited company is the third insurance company in the industry to obtain the qualification. The acquisition of this business qualification means that future customers will be able to purchase the required fund products through the agents of Ping'an life insurance and enjoy more comprehensive financial services. At the same time, it will bring new revenue growth for Ping'an life and accelerate the transformation of traditional life insurance agents to the integrated financial individual account manager.

In June 2013, the China insurance regulatory commission and the securities and futures commission jointly issued "the insurance agency sales of securities investment fund management interim provisions", the insurance company, insurance brokers and insurance agency, clear as the main body in the new fund sales. In fund sales eligible to apply for the life with the peace group integrated financial advantage, determine the Ping'an bank as the fund business regulatory 
bank, Ping'an bank third-party fund sales system (golden orange housekeeper) as the fund sales system. Ping'an insurance submitted the qualification application to the regulatory authorities in early June, 2014, and passed the onsite inspection in July, successfully obtaining the qualification approval of the fund sales business.

Financial development up to now, after insurance fund business qualification approved by Ping'an life insurance to the rising number of platform to handle the relevant fund business clients, it shows that more and more customers can fully enjoy the simple convenience brought about by the more comprehensive integrated financial services. According to statistics, in July 2014 to June 2015, Ping'an life insurance fund business net profit of 12.219 billion yuan, the bank net profit maximum reached 14.9 billion yuan, accounting for $43 \%$ of the group, the total net profit. It can be seen that the financial insurance fund business generates a considerable profit for the bank. In addition, the operation of the financial insurance fund business effectively promoted the transformation of the agent to the comprehensive financial account manager. Qualification for securities investment fund sales business, the next step will continue to strengthen the consignment fund business management experience, promote, and risk control ability, at the same time actively promote relevant personnel qualification certification on business on a commission basis funds and expertise to ascend, as always, for the general customers to provide "simple and convenient, friendly at ease" service.

\section{CONCLUSION}

Because China is still in the financial mode of separating operation and management, the basic regulation of financial mixed operation is not yet perfect. So, at the time of setting financial commodity investors insurance fund, we need not only to test the perfection of legislation, bur also weigh to the law of stability and flexibility, and constantly promote the application of mixed management in China. In today's financial situation, most developed countries begin to attach importance to the sound financial legal system, and thus develop financial services legal system that conforms to the law of financial market development. China should learn from and learn.

\section{REFERENCES}

[1] Yuan Cheng. An empirical test based on the VEC model of insurance effect in China's financial development $[\mathrm{J}]$. Economics and economics,2013(6); 162-166.

[2] Shen Liping, Wang Yue. A path analysis of the core competitiveness of China's insurance industry based on financial mixed operation [J]. Research on technology economy and management,2013(7):86-90.

[3] Ge Honglei. From China Ping'an acquisition of shenzhen development bank to see the road of the insurance industry [J]. Corporate culture (next issue),2013(7): 145.

[4] Hu Ting, wang jikang. Business operation, value creation and risk level of bank of China, a case study [J]. Economic problems exploration,2013(12):107-114.

[5] Chen Wei. Research on financial regulation in the transformation process of China's branch operation into mixed operation [J]. China business, 2013(18): 101-102.
[6] Zhai Yibo. Selection of domestic financial mixed operation mode and risk prevention analysis [J] financial development research,2015(1):55-60. 